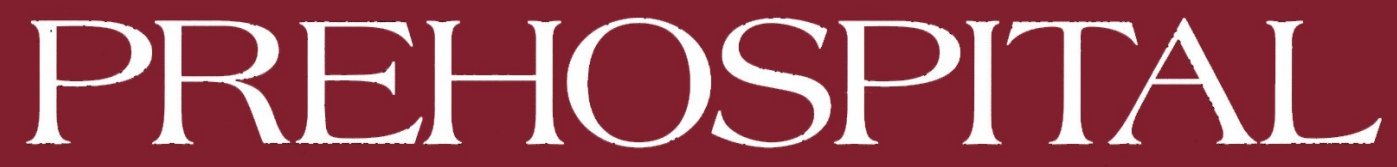
and
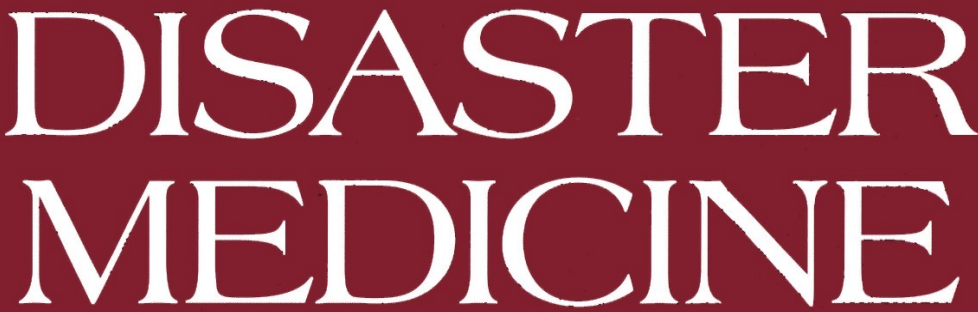

Médecine Pré-Hospitalière et Médecine de Catastrophe

Medicina Prehospitalária y de Catástrofes

病院にかかる前の処置し

炎害医癔

Volume 15, Number 3

July-September 2000

\begin{tabular}{|c|}
\hline Special Report \\
KAMEDO Report Summaries \\
Original Research \\
Medical Evacuation Programme for the 1999 Crisis in Kosovo \\
Brief Report \\
Bogus Doctors during Multi-Casualty Events and Disasters \\
Abstracts of Scientific Papers \\
Fifth Asia-Pacific Conference on \\
Disaster Medicine \\
Vancouver, British Columbia,CANADA \\
28 - 30 September, 2000 \\
Continuing Education \\
Fredrick C. Cuny Memorial Series \\
Group Dynamics in Disasters \\
Forum \\
Disasters and Therapeutic or Prophylactic Interventions \\
\hline
\end{tabular}

The Official Journal of the

World Association for Disaster and Emergency Medicine

and the

Nordic Society of Disaster Medicine 


\section{To the Rescue}

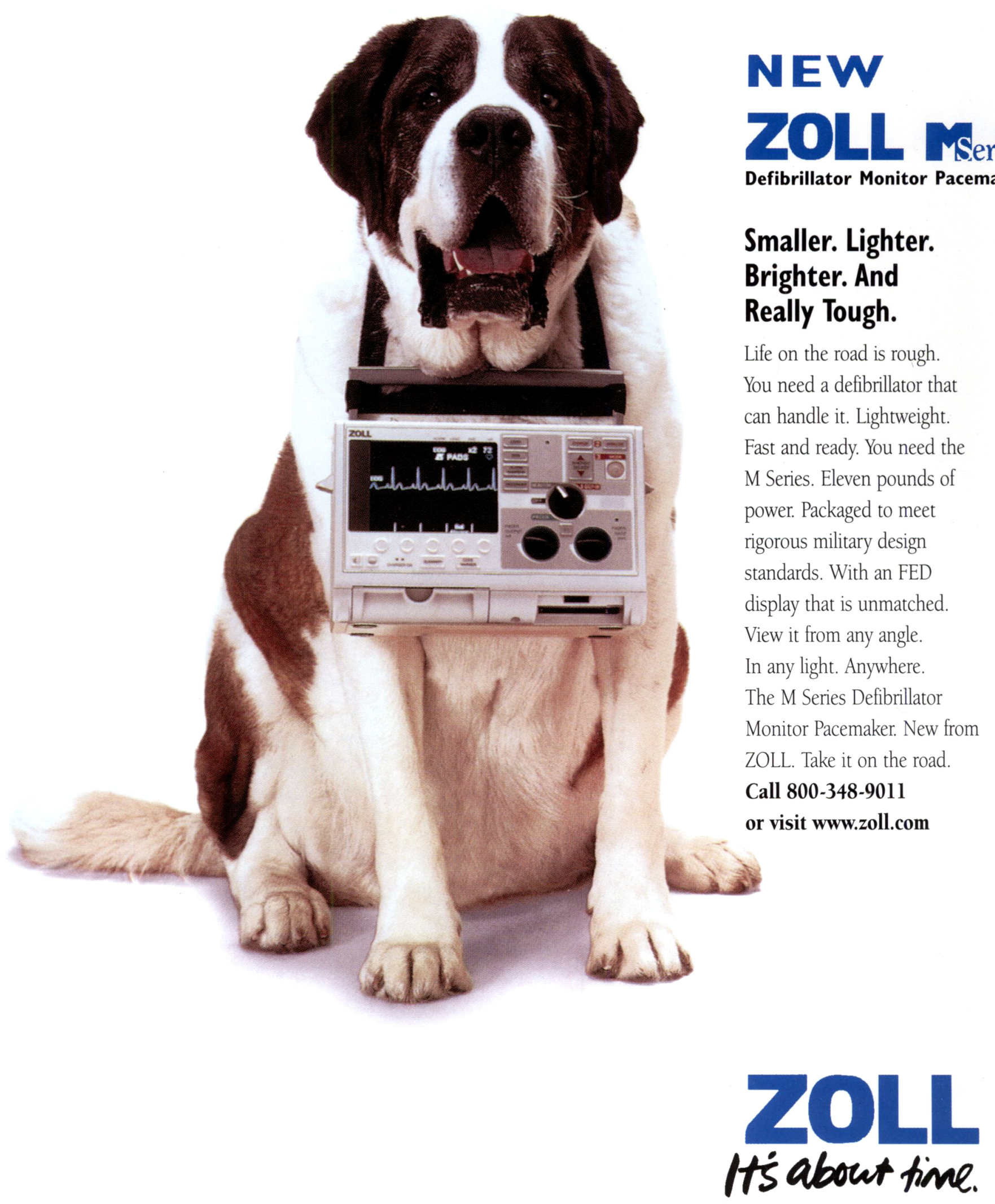



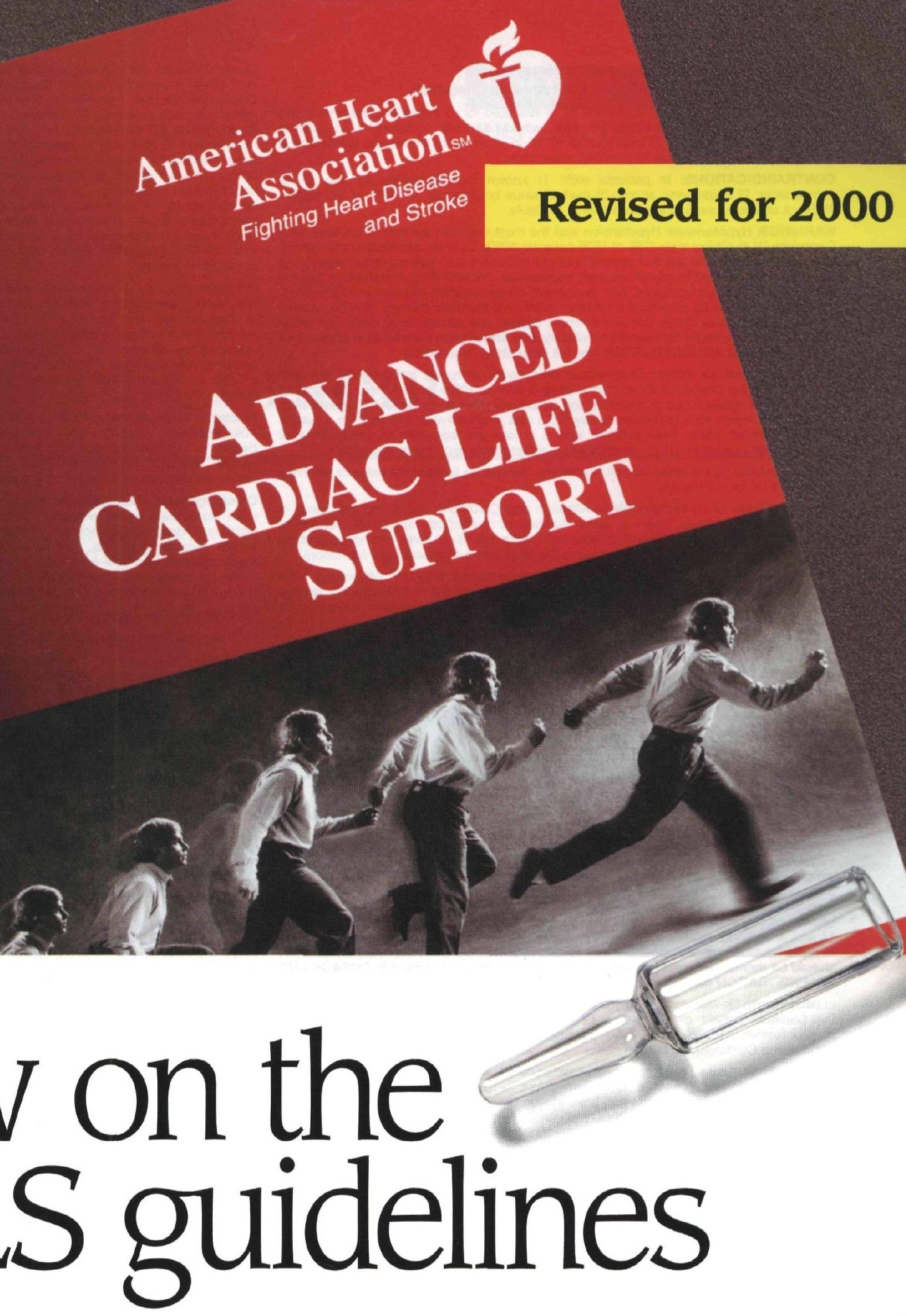

Cordarone I.V. is indicated for initiation of treatment and prophylaxis of frequently recurring ventricular fibrillation and hemodynamically unstable ventricular tachycardia in patients refractory to other therapy.

Cordarone I.V. is contraindicated in patients with cardiogenic shock, marked sinus bradycardia, and second- or third-degree AV block in the absence of a functioning pacemaker. Hypotension is the most common adverse effect seen with Cordarone I.V. and may be related to the rate of infusion. The most important treatment-emergent adverse effects are hypotension (16\%), bradycardia (4.9\%), liver function test abnormalities (3.4\%), cardiac arrest (2.9\%), VT (2.4\%), congestive heart failure $(2.1 \%)$, cardiogenic shock $(1.3 \%)$, and $\mathrm{AV}$ block $(0.5 \%)$.

Please see adjacent brief summary of Prescribing Information.
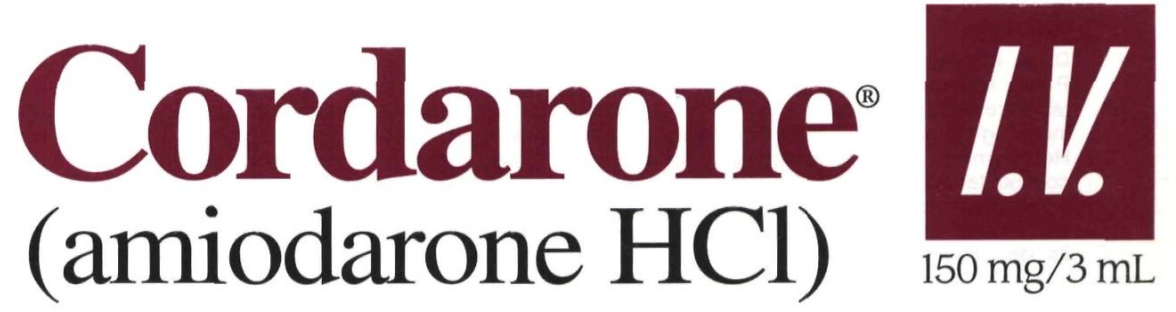
CORDARONE I.V. - Brief summary of prescribing information SEE PACKAGE INSERT FOR FULL PRESCRIBING INFORMATION

INDICATIONS AND USAGE: Cordarone (IV. is indicated for 1 ) initiation of treatment and prophylaxis of frequently recurring VF and hemodynamically unstable VT in patients refractory to other therapy; 2) treatment of VT/VF in patients for whom oral Cordarone is indicated, but who are unable to take oral medication.

CONTRAINDICATIONS: In patients with: 1) known hypersensitivity to any of its components; 2) cardiogenic shock; 3) marked sinus bradycardia; 4) 2nd- or 3rd-degree AV block unless a functioning pacemaker is available.

WARNINGS: Hypotension: Hypotension was the most common adverse effect seen with Cordarone IV. in clinical trials (288 of 1836 patients; $16 \%$ ). Clinically significant hypotension was most often seen in the first several hours of treatment and was not dose related, bu appeared to be related to rate of infusion. Hypotension necessitating alterations in therapy was reported in $3 \%$ of patients, with permanent discontinuation required in $<2 \%$. Treat was reported in $3 \%$ of patients, with permanent discontinuation required in $<2 \%$. Treat including vasopressor drugs, positive inotropic agents, and volume expansion. The initia rate of infusion should be monitored closely and should not oxceed that prescribed in DOSAGE AND ADMINISTRATION (see full prescribing information).

Bractycardia and AV Block: Drug-related bradycardia occurred in 90 (4.9\%) of 1836 patients receiving Cordarone I.V. in clinical trials; it was not dose related. Treat bradycardia by slowing the infusion rate or discontinuing Cordarone IV. In some patients, a pacemake is required. Despite such measures, bradycardia was progressive and terminal in 1 patien during controlled trials. Treat patients with a known predisposition to bradycardia or AV block with Cordarone I.V. in a setting where a temporary pacemaker is available.

Long-term Use: Se labeling for oral Cordarone. Experience is limited in patients receiving Cordarone IV. for $>3$ weeks.

Neonatad Hypo- or Hyperthyroidism: Although oral Cordarone use during pregnancy is uncommon, there have been a small number of published reports of congenita goiter/hypothyroidism and hyperthyroidism. If Cordarone IV. is given during pregnancy, apprise the patient of the potential hazard to the fetus (see full prescribing information).

PRECAUTIONS: Cordarone I.V. should be administered only by physicians who are experienced in the treatment of life-threatening arrhythmia with the risks and benefits of Cordarone, and have access to facilities adequate for monitoring the effectiveness and side effects of treatment.

Liver Enzyme Elevations: Elevations of blood hepatic enzyme values-ALT, AST, and GGT-are seen commonly in patients with immediately life-threatening VT/NF. Interpreting elevated AST activity can be difficult because values may be elevated in patients who have had recent myocardial infarction, CHF, or multiple electrical defibrillations. In clinica

studies, approximately $54 \%$ of patients

had baseline liver enzyme elevations

$13 \%$ had clinically significant elevations.
Liver enzyme elevations may improve during therapy or remain at baseline levels. Baseline abnormalities in hepatic enzymes are not a contraindication to treatment.

Two cases of fatal hepatocellular necrosis have been reported after Cordarone I.V. treatment of atrial arrhythmias with an initial infusion rate of $1500 \mathrm{mg}$ over 5 hours, a rate much higher than recommended. Both patients developed

hepatic and renal failure within 24 hours after the start of Cordarone I.V. and died on day 14 and 4 , respectively. Because these episodes of hepatic necrosis may have been due to rapid infusion rate with possible rate-related hypotension, the initial rate of infusion should be monitored closely and should not exceed that prescribed in DOSAGE AND ADMINISTRATION (see full prescribing information).

In patients with life-threatening arrhythmias, weigh the potential risk of hepatic injury against the potential benefit of Cordarone IV but carefully monitor patients for evidence of progressive hepatic injury. Give consideration to reducing administration rate or withdrawing Cordarone I.V. in such cases.

Proamhythmia: Like all antiarrhythmics, Cordarone IV. may cause a worsening of existing arrhythmias or precipitate a new arrhythmia. Proarrhythmia, primarily torsades de pointes, has been associated with prolongation by Cordarone I.V. of the QTC interval to $\geq 500 \mathrm{~ms}$. Although QTc prolongation occurred frequently in Cordarone IV patients, $\geq 500 \mathrm{~ms}$. Although QTc prolongation occurred frequently in Cordarone IV. patients,
torsades de pointes or new-onset VF occurred infrequently $(<2 \%)$. Monitor patients for torsades de pointes or new-onset VF occurred
QTC prolongation during Cordarone IV. infusion.

Pulmonary Disorders: AROS: Two percent of patients were reported to have adult respiratory distress syndrome (ARDS) during clinical studies. ARDS can arise after a variety of lung injuries, such as those resulting from trauma, shock, prolonged cardiopulmonary resuscitation, and aspiration pneumonia, conditions present in many of the patients resuscitation, and aspiration pneumonia, conditions present in many of the patients enrolled in the clinical studies. It is not possible to determine what role, if any,
played in causing or exacerbating the pulmonary disorder in those patients.

Postoperatively, ARDS has been reported in patients receiving oral Cordarone who have undergone either cardiac or noncardiac surgery. Although patients usually respond well to vigorous respiratory therapy, in rare instances the outcome has been fatal. Until further vigorous respiratory therapy, in rare instances the outcome has been fatal. Until further
studies are performed, $\mathrm{FiO}_{2}$ and the determinants of oxygen delivery to the tissues (e.g., $\mathrm{SaO}_{2}, \mathrm{PaO}_{2}$ ) should be closely monitored in Cordarone patients

Puimonary fibrosis: Only 1 of more than 1000 patients treated with Cordarone I.V. in clinical studies developed pulmonary fibrosis. In that patient, the condition was diagnosed 3 months after Cordarone I.V. treatment, during which time she received oral diagnosed 3 months after Cordarone l.V. treatment, during which time she received oral
Cordarone. Pulmonary toxicity is a well-recognized complication of long-term Cordarone use (see labeling for orat Cordarone).

Surgery: Close perioperative monitoring is recommended in amiodarone-treated patients undergoing general anesthesia as they may be more sensitive to the myocardial depressant and conduction effects of halogenated inhalational anesthetics.

Drug Interactions: Amiodarone can inhibit metabolism mediated by cytochrome P-450 enzymes, probably accounting for the significant effects of oral Cordarone (and presumably Cordarone I.V.) on the pharmacokinetics of various therapeutic agents including digoxin, quinidine, procainamide warfarin, dextromethorphan and cyclosporine. Hemodynamic and electrophysiologic interactions also have been observed after concomitant propranolol, diltiazem, and verapamil therapy. Agents producing a significant effect on amiodarone pharmacokinetics include phenytoin, cimetidine, and cholestyramine. Because of the long half-life of amiodarone, drug interactions may persist long after its discontinuation. Few data are available on drug interactions with Cordarone I.V.
Except as noted, the following summarizes important interactions between oral Cordarone and other therapeutic agents. Drugs Whose Effects May Be Increased (inc.) By Cordarone: Warfarin (prothrombin time inc.), Digoxin (sarum concentration inc.), Quinidine (serum concentration inc.), Procainamide (serum concentration, NAPA concentration inc.) Disopyramide (QT prolongation inc., which could cause arrhythmia), Fentanyl (may cause hypotension, bradycardia, decreased cardiac output), Flecainide (reduces the flecainide dose needed to maintain therapeutic plasma concentrations), Lidocaine (Oral: sinus bradycardia in 1 patient during local anesthesia; I.V.: seizure associated with inc. Ildocaine concentration observed in 1 patient), Cyclosporine (produces persistently elevated plasma concentrations of cyclosporine resulting in elevated creatinine, despite reduction in cyclosporine dose). Drugs That May Interfere With The Actions Of Cordarone: Cholestyramine (enterohepatic elimination of amiodarone inc.; may reduce serum levels and half-life), Cimetidine (serum amiodarone levels inc.), Phenytoin (decreases serum amiodarone levels).

Potential orug class interactions with Cordarone: Beta Blockers: Since Cordarone has weak beta-blocking activity, use with beta-blocking agents could increase risk of hypotension and bradycardia. Calcium Channel Blockers: Cordarone inhibits AV conduction and decreases myocardial contractility increasing the risk of AV block with verapamil or diltiazem or of hypotension with any calcium channel blocker. Volatile Anesthetic Agents: (see PRECAUTIONS, Surgery). In addition to the interactions above, chronic ( $>2$ weeks) oral Cordarone administration impairs metabolism of phenytoin dextromethorphan, and methotrexate.

Electrolyte Disturbances: Correct cases of hypokalemia or hypomagnesemia whenever possible before treating with Cordarone I.V., as these disorders can exaggerate the degree of QTC prolongation and increase the potential for torsades de pointes. Give special attention to electrolyte and acid-base balance in patients with severe or prolonged diarrhea or receiving concomitant diuretics.

Carcinogenesis, Mutagenesis, Impairment of Fertility: No carcinogenicity studies were conducted with Cordarone IV. However, oral Cordarone caused a statistically significant, dose-related increase in the incidence of thyroid tumors (follicular adenom and/or carcinoma) in rats. The incidence of thyroid tumors in rats was greater than the incidence in controls even at the lowest dose tested, i.e., $5 \mathrm{mg} / \mathrm{kg} /$ day (approx. 0.08 times the maximum recommended human maintenance dose*). Mutagenicity studies conducted with amiodarone $\mathrm{HCl}$ were negative.

No fertility studies were conducted with Cordarone IV. (see full prescribing information). * $600 \mathrm{mg}$ in a $50 \mathrm{~kg}$ patient (dose compared on a body surface area basis)

Pregnancy: Category D. See WARNINGS, Neonatal Hypo- or Hyperthyroidism. In has has caused a variety of adverse effects in animals (see full prescribing information). In a reproductive study in which amiodarone was given intravenously to rabbits at dosages about $0.1,0.3$ and 0.7 times the maximum recommended human dose (MRHD) on a body surface area dose (MRHD) on a body surface area broups, including controls. Embryotoxicity groups, including controls. Embryotoxicity
occurred at dosages of $0.3 \times$ MRHD and above. No evidence of embryotoxicity was observed at $0.1 \times$ MRHD and no dosages. In a teratology study in which amiodarone was administered by amiodarone was administered by continuous I.V. infusion to rats at dosages
about $0.4,0.7$, and 1.4 times the MRHD when compared on a body surface area basis, maternal toxicity and embryotoxicity were observed in the $1.4 \times$ MRHD group. Cordarone I.V. should be used during pregnancy only if the potential benefit to the mother justifies the risk to the fetus.

Nursing Mothers: Amiodarone is excreted in human milk; breast-feeding could expose the nursing infant to a significant dose of drug. Nursing offspring of lactating rats administered amiodarone demonstrated reduced viability and reduced body weight gains. Weigh the risk of exposing the infant to amiodarone against the potential benefit of arrhythmia suppression in the mother. Advise the mother to discontinue nursing

Labor and Delivery: It is not known whether use of Cordarone during labor or delivery has any immediate or delayed adverse effects. Prech

Pediatric Usage: Safety and efficacy of Cordarone in the pediatric population have not been established; such use is not recommended.

ADVERSE REACTIONS: In a total of 1836 patients in clinical trials, $14 \%$ received Cordarone IV. for $\geq 1$ week, $5 \%$ received it for $\geq 2$ weeks, $2 \%$ received it for 3 weeks, and $1 \%$ received it for $>3$ weeks, without an increased incidence of severe adverse reactions. The mean duration of therapy was 5.6 days; median exposure was 3.7 days. The most important treatment-emergent adverse effects were hypotension, asystole/cardiac arrest/EMD, cardiogenic shock, CHF, bradycardia, LFT abnormalities, VT, and AV block. Treatment was discontinued for about $9 \%$ of patients because of adverse effects, most commonly hypotension $(1.6 \%)$, asystole/cardiac arrest/EMD $(1.2 \%), V T(1.1 \%)$, and cardiogenic shock (1\%)

The following are the most common (incidence $\geq 2 \%$ ) and possibly drug-related adverse events during Cordarone I.V. clinical trials involving 1836 patients with life-threatening VT/VF. Data from all assigned treatment groups are pooled because none of the adverse events appeared to be dose-related: Fever, 2.0\%; Bradycardia, 4.9\%; CHF, 2.1\%; Heart arrest, 2.9\%; Hypotension, 15.6\%; VT, 2.4\%; LFTs abnormal, 3.4\%; Nausea, $3.9 \%$. Other possibly drug-related adverse events reported in $<2 \%$ of patents receiving Cordarone IV in clincal studies included abnormal kidney function, atrial fibrillation, diamhea, inc. ALT, inc. AST, lung edema, nodal arrhythmia, prolonged QT interval, respiratory disorder, shock, sinus bradycardia, Stevens-Johnson syndrome, thrombocytopenia, VF, and vomiting. In postmarketing survellance, toxic epidermal necrolysis, pancytopenia, neutropenia angioedema, and anaphylactic shock also have been reported.

This Brief Summary text is based on Direction Circular Cl 5032-3, Revised 5/7/99. 


\section{Table of Contents}

\section{Editor's Corner}

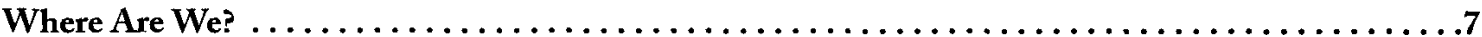

Marvin L. Birnbaum, MD, PbD

Special Report

KAMEDO Report Summaries

\section{Original Research}

Field Epidemiology Assessment for a Medical Evacuation Programme Related to the Crisis in Kosovo, 1999 ................................................19 Douglas W. MacPherson, MD, MSC(CTM), FRCPC; Fausto Mariani, MD; Jacqueline Weekers, MPH; Brian D. Gushulak, $M D$

\section{Brief Report}

Bogus Doctor Deceptions during Multi-Casualty Events and Disasters .25 Dr. Antony Nocera, FACEM; Ms. Anne M. Newton, B. Nursing, Dip. App. Sci.

\section{Continuing Education}

Fredrick C. Cuny Memorial Series

Principles of Disaster Management

Lessons 9: Group Dynamics in Disasters Fred C. Cuny

Fifth Asia-Pacific Conference on Disaster Medicine Abstracts for the Fifth Asia-Pacific Conference on Disaster Medicine Supplement 2

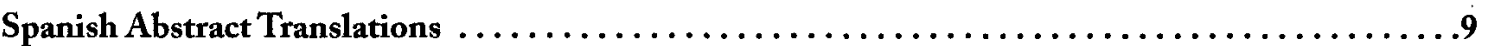

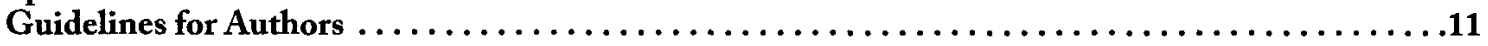

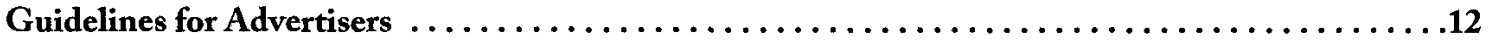

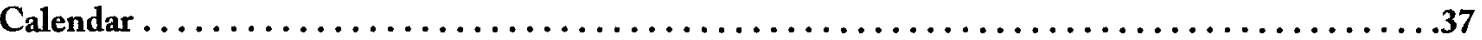

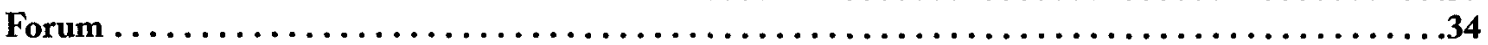




\section{Editorial Office}

University of Wisconsin-Madison USA

Marvin L. Birnbaum, MD, PhD, Editor-in-Chief

\section{Associate Editor \\ Colleen Heinkel}

\section{Production Editor}

Donna Schaan

\section{Web Production Editor Megan Phillips}

\section{Advertising}

Mary Duss

\section{Subscriptions}

Colleen Heinkel

\section{Editorial Office}

University of Wisconsin-Madison

\section{Publisher}

World Association for Disaster and

Emergency Medicine

Madison, Wisconsin USA
Prehospital and Disaster Medicine (ISSN 1049-023X) is published quarterly in the months of January, April, July, and October by the World Association for Disaster and Emergency Medicine. Prebospital and Disaster Medicine incorporates the Journal of the World Association for Emergency and Disaster Medicine and the Journal of Prebospital Medicine.

Editorial Information: Submit manuscripts and editorial inquiries to: Marvin L. Birnbaum, PhD, MD, Editor, Prehospital and Disaster Medicine, Clinical Science Center, 600 N. Highland (E5/615), Madison, WI 53792, USA; Telephone/Facsimile (01) (608) 263-9641; E-mail: mb@medicine.wisc.edu

Subscription Information: One year (four issues)-Institutions: (U.S.) $\$ 78$; Individuals: $\$ 55$; Canadian and international subscribers must add $\$ 15$ per year for postage. Claims of non-receipt or damaged issues must be filed within three months of cover date. POSTMASTER: Send address changes to Prehospital and Disaster Medicine, 1930 Monroe Street, Suite 304, Madison, WI 53711 USA.

Advertising Information: Mary Duss; Prehospital and Disaster Medicine, Clinical Science Center, 600 N. Highland (E5/615), Madison, WI 53792 USA

Abstracts: Comprehensively abstracted by the National Library of Medicine (Medline), Cumulative Index to Nursing and Allied Health (CINAHL) and Health Star Cumulative Index. The database is available online via BRS, DataStar, and DIALOG, and on CD-ROM through CD Plus, Compact Cambridge and Silver Platter. Abstracts and search capability available on the Internet at: http://pdm.medicine.wisc.edu.

Copyright $(2000$ by the World Association for Disaster and Emergency Medicine Periodicals postage paid at Madison, WI and at additional mailing offices 


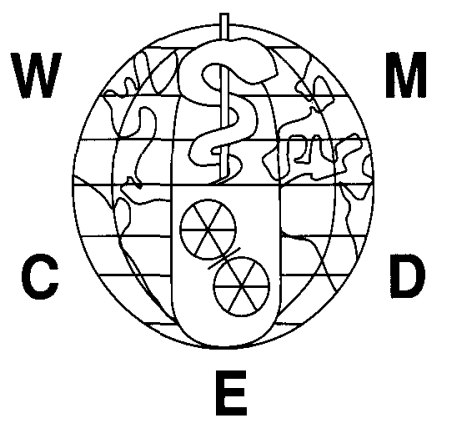

\section{$12^{\text {th }}$ World Congress on \\ Disaster and Emergency Medicine WADEM}

World Association for Disaster and Emergency Medicine

$$
\begin{gathered}
\text { May } 9 \text { - 12, } 2001 \\
\text { LYON, FRANCE }
\end{gathered}
$$

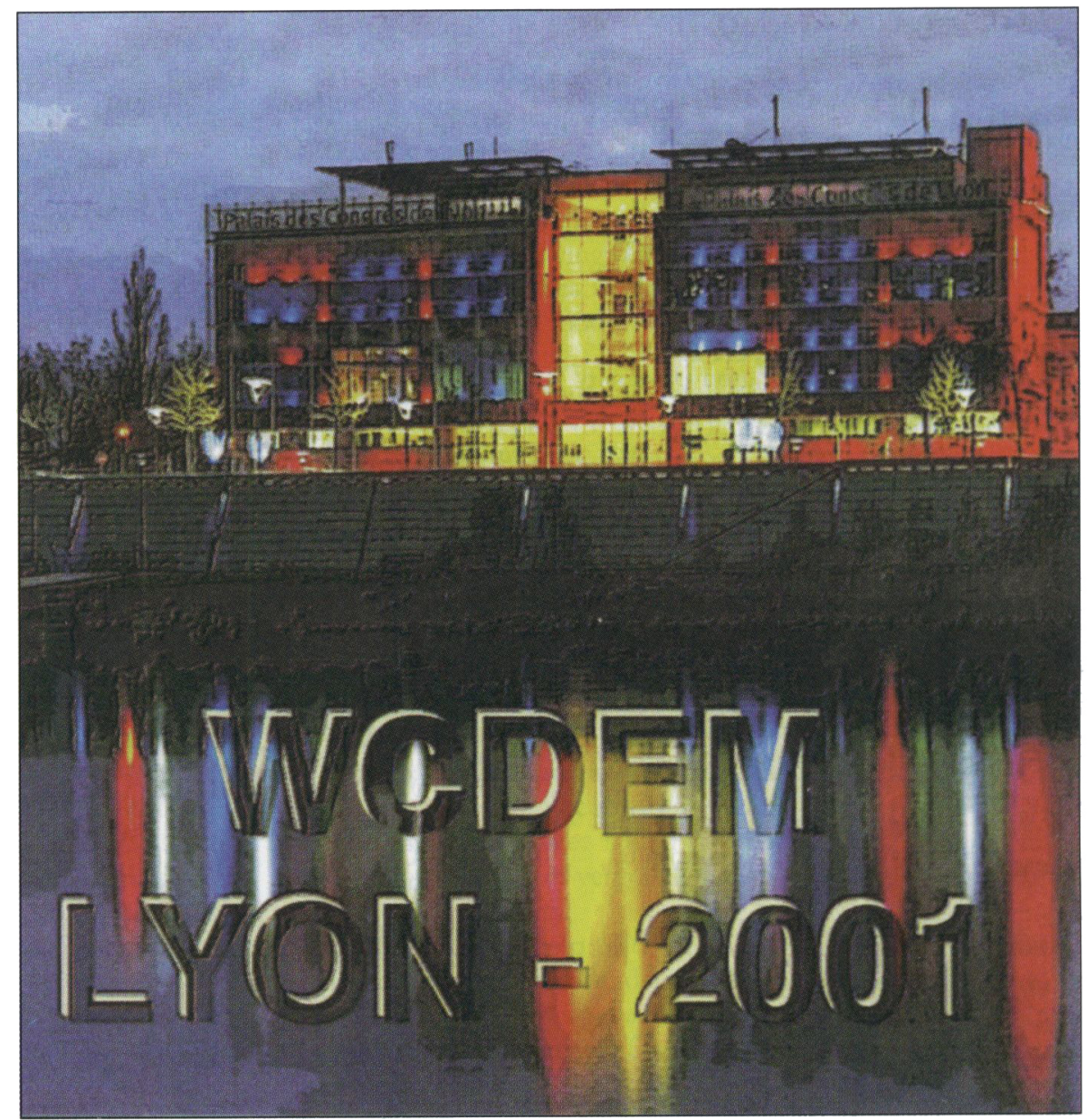


EDITOR-IN-CHIEF

Marvin L. Birnbaum, MD, PhD

University of Wisconsin-Madison

Madison, Wisconsin USA

ASSOCLATE EDITORS

Wolfgang Dick, Dr Med

Johannes Gutenberg Universität Mainz, Germany

Kimball Maull, MD

Carraway Injury Control Institute Birningham, Alabama USA

Ernesto A. Pretto, MD

University of Pittsburgh

Pittsburgh, Pennsylvania USA

Steven Rottman, MD

University of California-

Los Angeles

Los Angeles, California USA

\section{SECTION EDITORS}

Terrorism

Michael Moles, MD

Prince Philip Hospital

Hong Kong University

Hong Kong

\section{PAST EDITORS}

R Adams Cowley, MD

Deceased

(JWAEDM 1986-1987)

Peter Safar, MD

Safar Center

University of Pittsburgh

Pittsburgh, Pennsylvania USA

(JWAEDM 1981-1985)

Michael Gunderson, REMTP

Institute for Prehospital Medicine

Tempe, Arizona USA

CONSULTING EDITORS

S. William A. Gunn, MD

European Centre for Disaster Medicine

Geneva, Switzerland

Peter Safar, MD

Safar Center

University of Pittsburgh

Pittsburgh, Pennsylvania USA

Martin Silverstein, MD

Uniformed Services University of the Health Sciences

Bethesda, Maryland USA

Ronald Stewart, MD

Victoria Hospital

Halifax, Nova Scotia Canada

EDITORIAL BOARD

Jakov Adler, MD

Jerusalem, Israel

Ahmed Ammar, MD

Cairo, Egypt
V. Anantharaman, MD

Singapore General Hospital

Singapore

Paul B. Anderson

Lincoln Medical Education Foundation

Rural EMS Institute

Lincoln, Nebraska USA

Bishara Atiyeh, MD

American University

Beirut, Lebanon

Jack Ayres, JD, REMT-P

University of Texas Health Science Center

Dallas, Texas USA

Jan Babik, MD

Kosice Burn Center

Kosice-Saca, Slovakia

Peter Baskett, MD

Frenchay Hospital

Bristol, UK

Richard A. Bissell, PhD

University of MarylandBaltimore Campus

Baltimore, Maryland USA

Fredrick M. Burkle, MD, MPH

John A. Burns School of Medicine and School of Public Health

University of Hawaii

Honolulu, Hawaii USA

Jeff Clawson, MD

Medical Priority Consultants, Inc.

Salt Lake City, Utah USA

Felipe Cruz-Vega, MD

Social Security

Mexico City, Mexico

Richard O. Cummins, MD

University of Washington

Seattle, Washington OSA

Craig DeAtley, PA-C

George Washington University Medical Center

Washington, D.C. USA

Claude de Ville de Goyet, MD Pan-American Health Organization/World Health Organization

James DuCharme, MD

Royal Victoria Hospital

Montréal, Quèbec Canada

Judith Fisher, MD

British Association for

Immediate Care

London, UK

Malcolm Fisher, MD

Royal North Shore Hospital Sydney, Australia

Alain Flaujat, MD

Editor, Amelisap

Olonzao, France

Erik S. Gaull

TriData Corporation

Arlington, Virginia USA
Sergey Goncharov, MD

All-Russian Disaster Medicine Center

Moscow, Russia

Michael Gunderson, REMT-P Institute for Prehospital

Medicine

Tempe, Arizona USA

Borje Hallen, MD

Karolinska Sjukhuset

Stockholm, Sweden

Connie A. Jastremski, RN, MS

Syracuse, New York USA

Mark S. Johnson

Alaska Department of Public Health

Juneau, Alaska USA

Mark Keim, MD

Center for Disease Control and Prevention

Atlanta, Georgia, USA

Mark Klyachko, PhD

Center on Earthquake Engineering

Petropavlovek, Kam, Russia

Radana Konigova, MD

Charles University

Praque, Czech Republic

Per Kulling, MD

Swedish Poison Information Centre

Stockholm, Sweden

John C. Lane, MD

University of Campinas Medical Center

Sao Paolo, Brazil

Baxter Larmon, PhD, EMT-P

University of CaliforniaLos Angeles Medical Center Los Angeles, California USA

Todd J. LeDuc

Broward County Commission Ft. Lauderdale, Florida USA

Prof. Li Zhong-Hao, MD

Beijing Emergency Medical Center

Beijing, China

Susan D. McHenry

National Highway Traffic Safety Administration

Washington, D.C. USA

Sergio Magalini, MD

Universita Cattolicà del Sacro Cuore

Rome, Italy

Michele Masellis, MD

Osp. Reg. Civico

Palermo, Italy

Eric Noji, MD

Center for Disease Control and Prevention

Atlanta, Georgia, USA

Karl-Axel Norberg, MD, PhD

Stockholm, Sweden
Judy Olson, BSN, MEd

University of $W$ isconsin-Madison

Madison, Wisconsin USA

Muneo Ohta, MD

Senri Medical Center

Osaka, Japan

Paul Paris, MD

Center for Emergency Medicine

University of Pittsburgh Pittsburgh, Pennsylvania USA

Georg Petroianu, MD

University of Heidelberg Mannheim, Germany

Hugo Prado, MD

Pan-American Health

Organization/World Health

Organization

R Abdul Radjak, MD

Ministry of Health

Jakarta, Indonesia

Daniel Rodriguez, MD

San Jose, Costa Rica

Leonid B. Roshal, MD

Institute of Pediatrics

Academy of Medical Sciences

Moscow, Russia

Don Schramm

Disaster Management Center

University of $W$ isconsin

Madison, Wisconsin USA

Knut Ole Sundnes, MD

Baerum Hospital

Oslo, Norway

Frank Thomas, MD

Latter Day Saints Hospital

Salt Lake City, Utah USA

Shao Xiaohong, MD

Peking Union Redical College Chinese Academy of Medical Science

Beijing, China

Samuel Stratton, MD

Los Angeles County

Los Angeles, California USA

Takashi Ukai, MD

Osaka City General Hospital

Osaka, Japan

Yasuhiro Yamamoto, MD

Department of Emergency and Critical Medicine

Tokyo, Japan

Harsh Wardham, MD

Sundar Lal Jain Hospital Delhi, India 